\title{
Manual therapy and therapeutic exercise in the treatment of osteoarthritis of the hip: a systematic review
}

\author{
A. Romeo ${ }^{1,2}$, S. Parazza ${ }^{3}$, M. Boschi ${ }^{4}$, T. Nava ${ }^{5,6}$, C. Vanti ${ }^{2,4,7}$ \\ 'Orthopaedic Manipulative Physical Therapist, Private Practicioner, Bologna, Italy; \\ ${ }^{2}$ Manual Therapy, University of Padova, Italy; \\ ${ }^{3}$ Orthopaedic Manipulative Physical Therapist, Private Practicioner, Savignano sul Panaro (MO), Italy; \\ ${ }^{4}$ Orthopaedic Manipulative Physical Therapist, Private Practicioner, Castenaso (BO), Italy; \\ ${ }^{5}$ Physical Therapist, Liaison Office European League Against Rheumatism (EULAR); \\ ${ }^{6}$ Rheumatologic Rehabilitation, University of Vita Salute-San Raffaele (Milano) and University of Brescia, Italy; \\ ${ }^{7}$ Manual Therapy, University of Bologna, Italy
}

\section{SUMMARY}

This systematic review aimed at investigating the role of therapeutic exercise and/or manual therapy in the treatment of hip osteoarthritis (OA).

Two independent reviewers (AR, CV) searched PubMed, Cinahl, Cochrane Library, PEDro and Scopus databases and a third one (SP) was consulted in case of disagreement. The research criteria were publication period (from May 2007 to April 2012) and publication language (English or Italian).

Ten randomized controlled trials matched inclusion criteria, eight of which concerning therapeutic exercise and two manual therapy. Few good quality studies were found. At mid- and long-term follow-up land-based exercises showed insufficient evidence of effectiveness with respect to pain and quality of life, but positive results were found for physical function. Water exercises significantly reduced fall risk when combined with functional exercises. Programs containing progressive and gradual exposure of difficult activities, education and exercises promoted better outcomes, higher adherence to home program and increased amount of physical activity, especially walking. Manual therapy seemed to reduce pain and decrease disability at short-term. Less use of nonsteroidal anti-inflammatory drugs was statistically significant at long-term follow-up in patients treated with manual therapy. The relationship between clinical results and radiological grade of OA was not investigated. Encouraging results were found in recent literature for manual therapy and functional training. Further research is needed to elucidate this issue through high-quality trials, especially addressing the aspects that have not been thoroughly explored yet, for instance type, amount and scheduling of conservative treatment.

Key words: Osteoarthritis, Hip, Exercise, Manual therapy.

Reumatismo, 2013; 65 (2): 63-74

\section{INTRODUCTION}

$\mathrm{O}$ steoarthritis of the hip (OA) is characterized by focal areas of loss of articular cartilage, subchondral bone sclerosis and osteophytes. It causes noticeable disability and encompasses pain, loss of both mobility and muscular function, restriction of daily living activities and decreased quality of life $(1,2)$. It is a common musculoskeletal disorder and its frequency rapidly increases in people over 55 years, especially in western countries, therefore it has been considered as a worrying health issue.
The prevalence of this disease was investigated in Italian population by Cecchi et al. in 2008 , showing that $11.9 \%$ of Italian people aged 65 and older referred hip pain (3). In 2003 the ICARe Dicomano study showed hip osteoarthritis prevalence of $7.7 \%$ in Tuscan population older than 65 (4). In 2005, Salaffi et al. showed hip osteoarthritis global prevalence of $1.61 \%$ in another Italian region (Marche) (5).

The diagnosis of OA can be drawn with reasonable accuracy from patient's history and physical assessment, whereas final diagnosis is based on radiographic exams. The following clinical characteristics are
Corresponding author: Dott.ssa Carla Vanti Via Tosarelli 144 40055 Castenaso (BO), Italy E-mail: cavanti@tin.it 
typical for patients with radiological findings of OA: moderate pain while standing, pain referred to the anterior and lateral aspects of the hip, subjects older than 50 years, more than one hour of morning stiffness, limited passive range of motion at least to two out of six movement directions (6).

The most predictive finding for OA, confirmed by X-rays examination, is the decreased range of motion with a main restriction in internal rotation (7).

The criteria to classify OA were described in a multicentric trial conducted by the American College of Rheumathology (ACR) (8) and are largely accredited by several Guidelines.

Recommendations to manage OA by means of both pharmacological and nonpharmacological modalities have been produced by the European League Against Rheumatism (EULAR) (9), and more recently by the ACR (10). In order to relieve symptoms, pharmacological treatment is based on the prescription of paracetamol and oral non-steroidal anti-inflammatory drugs (NSAIDs).

The use of opioid analgesics is exclusively recommended in case other treatments fail, whereas the use of Slow Acting Symptomatic Drugs is more controversial.

Conversely, there is strong agreement that patients with symptomatic OA should be enrolled in exercise programs and lose weight (if overweight), possibly in association with manual therapy, while information on the use of thermal agents and walking aids, if needed, should be given $(9,10)$.

Manual therapy and therapeutic exercise are suggested to relieve pain and improve function and quality of life (11). Although these treatments are recommended by Guidelines, they have not been prescribed frequently, in fact only $28 \%$ of patients are suggested to follow them (12). Moreover, the existing systematic reviews cast doubts on the effectiveness of those therapeutic indications.

Thus, the aim of this study is to systematically review the efficacy of therapeutic exercise and/or manual therapy, in order to update the therapeutic indications that previous studies provided.

\section{METHODS OF RESEARCH}

Two independent reviewers (AR, CV) searched PubMed, Cinahl, Cochrane Library, PEDro and Scopus databases and a third one (SP) was consulted in case of disagreement.

The following research string was used in PubMed, Cinahl, Cochrane Library, and Scopus databases: ["hip osteoarthritis" OR coxarthrosis] AND exercise OR "manual therapy" OR "mobilization treatment" OR stretching OR strengthening OR hydrotherapy NOT ["hip arthroplasty" OR "hip arthroprosthesis"].

The following key words were used and combined to search PEDro: hip osteoarthritis and coxarthrosis, matched with stretching, mobilization, manipulation, massage, or strength training, or fitness training, or hydrotherapy, balneotherapy.

Furthermore, other studies were included after we examined the references of retrieved studies.

The research criteria were publication period (previous 5 years, from May 2007 to April 2012), language (English or Italian), and type of study (randomized controlled trials, RCT).

RCTs were included if they concerned the efficacy of therapeutic exercise and/or manual therapy in patients with clinical or radiological diagnosis of OA. Studies concerning both knee OA and hip OA were included only if they independently analyzed results regarding these two joints. Interventions could include every kind of therapeutic exercise such as aquatic therapy, land-based exercise and/or manual therapy, regardless of its type, duration, frequency and intensity.

We included RCTs that used the following outcome measures: pain intensity, physical function, aerobic capacity, disease progression, quality of life, use of medications, and costs.

The exclusion criteria were pre- or posthip arthroplasty surgery treatment, educa- 
tional and therapeutic treatment based on unconventional therapies, such as Yoga and Tai Chi, or interventions based on either assumptions or methodologies not coherent with therapeutic exercise and manual therapy.

The studies matching inclusion criteria were scored with the PEDro Scale (13) and only studies that scored $7 / 10$ were considered to be qualitatively sufficient. Furthermore, eight systematic reviews were examined and included in the Discussion, seven of which concerned therapeutic exercise and one manual therapy.

\section{RESULTS}

The research provided 1534 studies, excluding double citations. We excluded 1507 and 13 studies after we read study's title and abstract respectively, since they did not meet inclusion criteria. For the same reason, we did not include four studies after we read full text.

Ten RCTs matched inclusion criteria (1423). Eight RCTs concerned therapeutic exercise $(14-19,22,23)$ and two manual therapies $(20,21)$. Figure 1 depicts the selection process, Table I shows PEDro scale items, and Table II includes the selected RCT with a brief description.

We found a scarce amount of studies, treatment procedures were heterogeneous and sample size was small. Hence, it was not possible to conduct a meta-analysis in order to statistically evaluate results.

With respect to therapeutic exercise, the results of this review reported that evidence of efficacy in reducing pain was insufficient or limited, whereas moderate evidence was found in improving function. Moreover, booster sessions had a positive role on increasing patient's adherence to treatment (17).

Three studies investigated the effectiveness of land-based exercises $(14,15,22)$. These works demonstrated no evidence of effectiveness with respect to pain at mid- and long-term follow-up, but showed positive results for physical function.

More specifically, Juhakosky et al. (15) compared exercise effectiveness with General Practitioner Care and they observed a progressive improvement of physical function within the experimental group at 3,6 and 18 months follow-up. They suggested that exercise might produce positive outcome, which gradually ameliorates over the time.

Nevertheless, these results did not imply a reduction of costs in comparison with the control group.

Furthermore, a home strengthening program seemed feasible even in patients with severe OA, even though no significant improvement was observed (22).

Other three works investigated the combined effect of exercise, education and therapeutic strategies for functional training. Murphy et al. (18) adopted a program by following concepts of behavioral treatment, which was addressed to the daily activities that were difficult to perform (activity pacing).

Although subjective assessment did not show any relevant differences, adding this program to exercise and education seemed to be effective at mid-term follow-up (6 months) with regard to the amount of daily functional activities, which were measured by means of accelerometer.

Pisters et al. $(16,17)$ investigated the effectiveness of behavioral graded activity (BGA) method, which consisted of programs based on the functional characteristics of patients.

The most problematic daily life activities were gradually increased by means of time-contingent modalities.

Exercise programs had the aim of reducing impairments that affected the performance of such activities.

As far as short- and mid-term outcomes of pain and function, progressive and gradual exposure of difficult activities and exercise seemed to enhance outcomes (17), improve adherence to home program and increase amount of physical activity, especially walking (16). At long-term follow-up (5 years) the only significant difference for the group, which followed the BGA program, was related to less use of prosthesis surgery (17). 
Two papers $(19,23)$ focused on water exercise, by employing therapeutic programs containing warm-up, strengthening for upper and lower limbs, trunk control and postural exercises, balance and cool-down. Whilst Hale et al. (19) did not show any effectiveness of water program for improv- ing function and decreasing fall risk, Arnold and Faulkner (23) demonstrated that those who performed both water exercises and land-based functional exercises significantly reduced their fall risk, compared to those who did only water exercises and to controls.

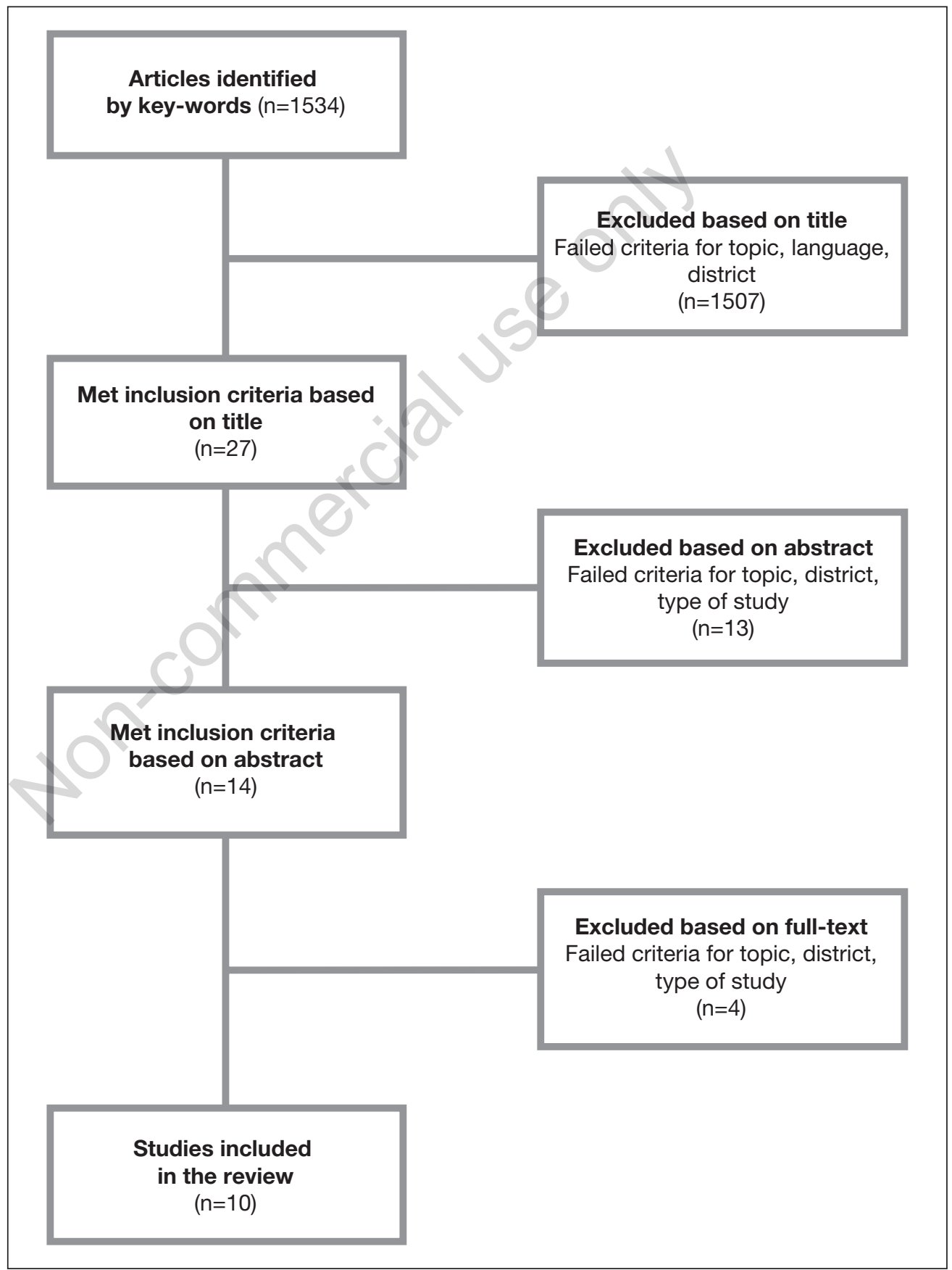

Figure 1 - Flow chart. 
Only one study compared different dosages of manual therapy (20). In particular, techniques of joint mobilization such as longitudinal traction with intensity up to 800 $\mathrm{N}$, were compared to the same technique, but with unknown dosage. The treatment of the experimental group (known dosage) showed short-term reduction of pain and decreased disability.

Another study (21) compared manual approaches, addressed to the whole kinetic chain of the lower limb in association with exercise, with another approach focusing on the hip only, always in association with exercise. No significant difference between the two groups was found.

As regards the compliance, two studies $(15,17)$ investigated the role of patient's adherence to treatment on clinical out-

Table 1 - PEDro scale.

\begin{tabular}{|l|l|l|}
\hline Eligibility criteria were specified & no & yes \\
\hline $\begin{array}{l}\text { Subjects were randomly allocated to } \\
\text { groups (in a crossover study, subjects } \\
\text { were randomly allocated an order in } \\
\text { which treatments were received) }\end{array}$ & yes \\
\hline Allocation was concealed & no & yes \\
\hline $\begin{array}{l}\text { The groups were similar at baseline } \\
\text { regarding the most important } \\
\text { prognostic indicators }\end{array}$ & no & yes \\
\hline \begin{tabular}{l} 
There was blinding of all subjects \\
\hline $\begin{array}{l}\text { There was blinding of all therapists } \\
\text { who administered the therapy }\end{array}$
\end{tabular} & no & yes \\
\hline $\begin{array}{l}\text { There was blinding of all assessors } \\
\text { who measured at least one key } \\
\text { outcome }\end{array}$ & no & yes \\
\hline $\begin{array}{l}\text { Measures of at least one key outcome } \\
\text { were obtained from more than } 85 \% \\
\text { of the subjects initially allocated to } \\
\text { groups }\end{array}$ & no & yes \\
\hline $\begin{array}{l}\text { All subjects for whom outcome } \\
\text { measures were available received } \\
\text { the treatment or control condition } \\
\text { as allocated or, where this was not } \\
\text { the case, data for at least one key } \\
\text { outcome was analysed by intention } \\
\text { to treat }\end{array}$ & no & yes \\
\hline $\begin{array}{l}\text { The results of between-group } \\
\text { statistical comparisons are reported } \\
\text { for at least one key outcome }\end{array}$ & no & yes \\
\hline $\begin{array}{l}\text { The study provides both point } \\
\text { measures and measures of variability } \\
\text { for at least one key outcome }\end{array}$ & no & yes \\
\hline
\end{tabular}

comes. Juhakoski et al. (15) showed that the compliance tended to decrease in relation to fewer amounts of sessions and to time. Pisters et al. (17) demonstrated that the educational component of the program and the functional training increased patient's adherence to therapeutic indications.

Quality of life was investigated only in three studies $(15,19,20)$. Juhakoski et al. (15) administered the physical functioning subscale of SF-36; Hale et al. (19) the arthritis impact measurement scales 2-short form - 26 items (AIMS2-SF), and Vaarbakken et al. (20) the hip-related quality of life (HR-QL).

Despite these different authors employed different scales of quality of life, in their studies no significant results were obtained between experimental and control groups on this outcome measure.

Concerning pharmacological treatments, no study investigated the concomitant use of medication in experimental and control groups, to deepen the possible confounding effect of drugs on clinical outcomes. Only one study (15) considered the use of medication as outcome measure and showed a statistically significant reduction of the use of NSAIDs in the group treated with manual therapy at 12 and 18 months follow-up. Nevertheless, no difference was found for paracetamol and weak opioids use.

Pisters et al. (16) considered as inclusion criterion the radiological evidence of OA, but they did not investigate the relationship between X-rays grading [Kellgren/ Lawrence (KL) index] and clinical outcomes. Only the paper of Juhakoski et al. (15) specified the difference of X-rays grading in both samples (experimental and control groups).

In this work, inclusion criteria comprehended OA with KL grade $\geq 1$ and authors compared KL scores between intervention and control groups. Most part of the sample presented KL grade 1 or KL 2 grade, and no significant difference between groups was found. However, the relationship between clinical results and severity of KL grade was not investigated. 
Table 2 - Description of randomized controlled trials.

\begin{tabular}{|c|c|c|c|}
\hline Author & $\begin{array}{l}\text { PEDro } \\
\text { score }\end{array}$ & Treatment & Sample \\
\hline $\begin{array}{l}\text { Vaarbakken } \\
\text { and Ljunggren, } \\
2007 \text { (20) }\end{array}$ & $7 / 10$ & $\begin{array}{l}\text { Group I: } 15 \text { ' of manual traction per session. Traction duration: } 20 "-40 " \\
\text { Strengthening exercises, stretching and soft tissues massage: duration } \\
\text { not reported. } \\
\text { Group C: mobilization and traction with non-standardized force, soft } \\
\text { tissues massage, information and exercises. } \\
\text { Groups I and C: } 2 \text { weekly sessions of } 30 \text { ' per } 12 \text { weeks. }\end{array}$ & $\begin{array}{l}\text { Group l: } \\
n=10, a .62 \pm 14 \\
\text { Group C: } \\
n=9, \text { a. } 57 \pm 21\end{array}$ \\
\hline $\begin{array}{l}\text { Murphy et al., } \\
2008 \text { (18) }\end{array}$ & $7 / 10$ & $\begin{array}{l}\text { Group I: Exercises (Ex) + activities training and strategy (AST). } \\
\text { Group C: Exercises (Ex) + education (Ed). } \\
\text { Groups I e C: } 1.5 \mathrm{~h} \text { per week, } 245 \text { '-sessions, for } 4 \text { weeks. Same } \\
\text { exercises in both Groups. Two recall sessions at two months. }\end{array}$ & $\begin{array}{l}\text { Group l: } \mathrm{n}=6 \\
\text { a. } 74.8 \pm 7.3 \\
\text { Group C: } \mathrm{n}=26 \\
\text { a. } 75.8 \pm 7.1\end{array}$ \\
\hline $\begin{array}{l}\text { Shrier et al., } \\
2008 \text { (22) }\end{array}$ & $5 / 10$ & $\begin{array}{l}\text { Group l: Specific strengthening home exercises based on initial } \\
\text { assessment. Variable frequency (not-standardized), 10'- to 20'-min } \\
\text { sessions. } \\
\text { Group C: Usual care: no intervention. }\end{array}$ & $\begin{array}{l}\text { Group I: } n=8 \\
\text { a.65. } 1 \pm 8 \\
\text { Group C: } n=7 \\
\text { a. } 65.6 \pm 10.7\end{array}$ \\
\hline $\begin{array}{l}\text { Arnold and } \\
\text { Faulner, } \\
2010 \text { (23) }\end{array}$ & $6 / 10$ & $\begin{array}{l}\text { Group l: Aquatic Exercise + Education (AE). With regards to exercise } \\
\text { there are the same as A (see below). With regards to Education is a 30' } \\
\text { educational session preceding the aquatic class, once a week per } 11 \\
\text { weeks. } \\
\text { Group Ib: Only Aquatic Exercise (A) } 1.5 \mathrm{~h} \text { per week, } 245 \text { '-sessions, for } \\
11 \text { weeks (warm up ex's, lower and upper extremity strengthening ex's, } \\
\text { trunk control ex's, posture practice, balance ex's, cool down). } \\
\text { Group C: Usual activities, none exercise program during the same } \\
\text { intervention period. Adherence encouraged by phone call every } 2 \\
\text { weeks. }\end{array}$ & $\begin{array}{l}\text { Group I (AE): } \mathrm{n}=28, \\
\text { a.73.2 } 44.8 ; \\
\text { Drop out (DO)=5 } \\
\text { Group Ib (A): } \mathrm{n}=26 \text {, a. } \\
74.4 \pm 7.5 ; \mathrm{DO}=7 \\
\text { Group C: } \mathrm{n}=25, \\
\text { a. } 75.8 \pm 6.2 ; \mathrm{DO}=6\end{array}$ \\
\hline $\begin{array}{l}\text { Fernandes et al., } \\
2010 \text { (14) }\end{array}$ & $8 / 10$ & $\begin{array}{l}\text { Group I: PE (Patient Education). Specific "Hip school" for hip OA. } 3 \\
\text { Group-sessions and } 1 \text { individual session after } 2 \text { months. } \\
\text { Group C: PE+ SE (Supervised Exercise). SE started } 1 \text { week after PE, } \\
\text { consisted of max } 26 \text { standard exercises, supervised sessions } 2 \text { times a } \\
\text { week per } 12 \text { weeks. }\end{array}$ & $\begin{array}{l}\text { Group l: } n=54 \\
\text { a. } 57.2 \pm 9.8 \\
\text { Group C: } n=55 \\
\text { a. } 58.4 \pm 10.0\end{array}$ \\
\hline $\begin{array}{l}\text { Pisters et al., } \\
2010 \text { (17) }\end{array}$ & $8 / 10$ & $\begin{array}{l}\text { Group I: BGA (Behavioral Graded Activity): tailored exercises, maximum } \\
\text { of } 18 \text { sessions in } 12 \text { weeks. Further home exercises were advised. } \\
5 \text { recall sessions at the } 18 \text { th, } 25 \text { th, 34th, } 42 \text { th, } 55 \text { th weeks (max } 7 \\
\text { sessions). } \\
\text { Group C: UC (Usual Exercise Therapy): maximum of } 18 \text { sessions in } 12 \\
\text { weeks. } \\
\text { Group I e Group C: } 30 \text { '-session duration in both Group I and Group C. }\end{array}$ & $\begin{array}{l}\text { Group } l: n=97 \text {, } \\
\text { a. } 65.1 \pm 7.4 \text {. } \\
\text { At } 60 \text { months-follow- } \\
\text { up: } n=76 \text {. } \\
\text { Group C: } n=103 \text {, } \\
\text { a.4.5 } 58.3 \text {. } \\
\text { At } 60 \text { months-follow- } \\
\text { up: } n=73 \text {. }\end{array}$ \\
\hline $\begin{array}{l}\text { Pisters et al., } \\
2010 \text { (16) }\end{array}$ & $8 / 10$ & $\begin{array}{l}\text { Group I: BGA (Behavioral Graded Activity): tailored exercises, maximum } \\
\text { of } 18 \text { sessions in } 12 \text { weeks. Further home exercises were advised. } 5 \\
\text { recall sessions at } 18,25,34,42,55 \text { weeks (max } 7 \text { sessions). } \\
\text { Group C: UC (Usual Exercise Therapy): maximum of } 18 \text { sessions in } 12 \\
\text { weeks. } \\
\text { Group I e Group C: } 30 \text { '- session duration in both Group I and Group C. }\end{array}$ & $\begin{array}{l}\text { Group } l: n=97 \text {, } \\
\text { a. } 65.1 \pm 7.4 \text {. } \\
\text { At } 60 \text { months-follow- } \\
\text { up: } n=76 \text {. } \\
\text { Group } C: n=103 \text {, } \\
\text { a.4.5 } 8.3 \text {. } \\
\text { At } 60 \text { months-follow- } \\
\text { up: } n=73 \text {. }\end{array}$ \\
\hline
\end{tabular}


Primary Outcomes: Pain measured with WOMAC (Western Ontario and MacMaster Osteoarthritis Index), subjective Physical Activities (PA) measured with CHAMPS (The Communinity Health Activities Model Program for Seniors). Objective PA measured with actiwatch (wrist accelerometer). Secondary Outcomes: Arthritis Self-Efficacy Scale, Physical Function measured with Six-Minute Walk Test and Timed up and go Test.

Primary Outcome: WOMAC Questionnaire

Secondary Outcomes: 50 Foot Walk Test and Timed Stair Climb Test, VAS and SF-36 (physical functioning subscale).
Results

Group I: HOOS improvement total score 43\% ( $\mathrm{P}=0.002)$; HOOS disability: reduction in all subjects; HOOS pain: $63 \%$ reduction $(\mathrm{P}=0.005)$.

Group C: HOOS improving total score 3\% ( $P=0.002)$; HOOS disability: 5 out of 9 subjects- conditions improved and 4 out of 9 worsened; HOOS pain: $25 \%$ reduction ( $P=$ 0.005).

Pain: Diminished in both Groups (-1.2 in Group C e -1.5 in Group I. No significant differences between the 2 Groups and small Effect Size (ES) $(\mathrm{d}=0.03)$.

CHAMPS total PA and PA subjective peak: significant effect only in Group for $P A$ peak $[\mathrm{F}=5.9, \mathrm{P}=0.02$ ) with small ES (d=0.30). Arthtritis Self-Efficacy Scale and Physical Function: no significant differences between Groups. SixMinute Walk Test: Both Groups improved at post-test time. WOMAC: no significant difference $(P=0.69)$ at baseline between subjects who completed the study [47.7 \pm 22$]$ and those who did not [44.6 \pm 23.1$]$.

Group C: slightly worsened for functioning sub scale, but slightly improved for stiffness subscale (not statistically significant)

SF-36: (physical functioning subscale): Group $\mathrm{C}$ was found to worsen less than other groups.

Primary Outcomes:

- BBSm (/36): Berg Balance Scale modified.

- 6-min walk (m)

- Chair stands (30-s)

- ABC (/100): Activities and Balance Confidence

- TUG (s): Timed up-and-go test.

Secondary Outcomes:

- AIMS-2 (The Arthritis Impact Measurement Scale)

- PASE (The Physical Activity Scale for the Elderly).

Primary Outcome: WOMAC Pain subscale . Secondary Outcomes: WOMAC (Stiffness and Physical Function subscales); SF-36v2; Modified Norwegian version of PASE (Physical Score for Elderly).

\section{Exercise adherence: 5-points scale.}

SQUASH (Short Questionnaire to Assess Health Enhancing Physical Activity) to measure physical activity. Recommendation for physical activity: Moderate aerobic activity (at least 30') 5 times a week or intense aerobic activity (at least) 20' 3-4 times a week.

Outcomes measured at baseline and at 13 th and $65^{\text {th }}$ weeks.

Primary Outcomes: WOMAC (Pain and Physical Function), PGA (Patient Global Assessment), with 8-point scale.

Secondary Outcomes: MACTAR Questionnaire (McMaster Toronto Arthritis Questionnaire - Physical Function), 5- MeterWalking-Test (Physical Performance).

Primary and Secondary Outcomes: Measured at 3, 9, 15 e 60 months.
PASE: No significant difference in physical activity level among the 3 groups at baseline or at post-test.

AIMS-2: No significant difference in physical activity level between the 3 groups at baseline or at post-test.

- Fall risk factors: No significant difference between the 3 groups.

- Significant difference between dropouts (DO) and completers for fall history and other risk factors.

- For completers ( $A E=23, A=19, C=19$ ) only, there were significant differences in primary fall risk variables: chair stand (AE better than $A$ and than $C$ ) and $A B C$ ( $A E$ better both than $\mathrm{A}$ and $\mathrm{C}$ )

WOMAC Pain: no significant difference at 16-months follow-up.

WOMAC Physical Function: Significant improvement in ( $\mathrm{P}=0.011)$ Group $C$ with respect to Group I.

WOMAC Stiffness, SF-36, PASE: no significant differences.

Group I: Better adherence to home exercises and activities with respect to Group C both in short- and long- term.

Greater amount of subjects who followed recommendation for physical activity.

Increase of physical activity, mostly with respect to walking-time.

Group I: Hip articular prosthesis risk reduced mostly with respect to Group $\mathrm{C}$ as better outcome result at short- and long- term.

Group I and Group C: long-term benefits. No significant differences between Groups with respect to pain, physical function and PGA. 


\begin{tabular}{|c|c|c|c|}
\hline $\begin{array}{l}\text { Juhakoski et al., } \\
2011 \text { (15) }\end{array}$ & $7 / 10$ & $\begin{array}{l}\text { Group l: Exercises (Ex) + General Pratictioner Care (GP). } \\
12 \text { supervised sessions (1 per week, } 45 \text { min) and } 4 \text { recall sessions after } \\
1 \text { year (12- e } 13-\text { months follow-up). } \\
\text { Group C: Only GP and analgesic drugs }\end{array}$ & $\begin{array}{l}\text { Group l: } n=60 \\
\text { a. } 66.9 \pm 6.3 \\
\text { Group C: } n=58 \\
\text { a. } 66.3 \pm 6.6 \text {. }\end{array}$ \\
\hline $\begin{array}{l}\text { Brantingham } \\
\text { et al., } \\
2012(21)\end{array}$ & $8 / 10$ & $\begin{array}{l}\text { Group I: MMT (Manual and Manipulative Therapy) about full kinetic } \\
\text { chain + Ex (Exercises) with stretching of hip muscles before and after } \\
\text { treatment. } \\
\text { Group C: MMT + Ex (exercises) with stretching of hip muscles before } \\
\text { and after treatment. } \\
\text { Group I and Group C: General advices about exercises only after the } \\
\text { 5th week (9th session). Total of } 9 \text { sessions in } 5 \text { weeks and 3-months } \\
\text { follow-up. }\end{array}$ & $\begin{array}{l}\text { Group C: } n=58 \\
\text { a. } 62.8 \pm 10.3 \\
\text { Group } I: n=53 \\
\text { a. } 63.3 \pm 10.7\end{array}$ \\
\hline $\begin{array}{l}\text { Hale et al., } \\
2012 \text { (19) }\end{array}$ & $8 / 10$ & $\begin{array}{l}\text { Group I: water exercises } 2 \text { times a week for } 12 \text { weeks. Session duration } \\
\text { from } 20^{\prime} \text { (1st week) to 60'(9th week). } \\
\text { Group C: Computer training } 2 \text { times a week for } 12 \text { weeks. Session } \\
\text { duration: } 60 \text { '. }\end{array}$ & $\begin{array}{l}\text { Subjects } n=39 \text {. } \\
\text { a. } 75 \pm 1, . \\
\text { Group I: } n=23 \\
\text { (a.75.7 } \pm 1.1 \text { ) } \\
\text { Group C: } n=16 \\
\text { (a.73.6 } \pm 1.5 \text { ) }\end{array}$ \\
\hline
\end{tabular}

I, intervention group; C, control group; n, sample size; a., sample's average age.

\section{DISCUSSION}

Given the considerable amount of studies, which supported their efficacy, manual therapy and therapeutic exercise become cornerstones of conservative treatment of patients with osteoarthritis of the lower limb.

The main goals of exercise and manual therapy in these patients are pain relief and enhancement of function, as well as social participation. Manual therapy and therapeutic exercise help reduce pain and improve muscular strength, joint range of motion, proprioception, balance and cardiovascular fitness. Furthermore, exercise can improve physical performance, weight control and overall psychological condition (24).

In spite of this, research on treatment of OA with exercise and manual therapy is qualitatively and quantitatively inferior if compared with other districts or joints. This is in contrast with the epidemiological relevance of such musculoskeletal disorder and with the suggestions of Guidelines that agree with the relevance of these therapeutic tools. Thus, recommendations were mostly based on expertise.

Furthermore, several old studies included patients affected by both hip and knee arthritis, by adopting not a stratified but a combined randomization, thus affecting negatively the sample homogeneity. In conducting a meta-analysis, sample homogeneity reduces the amount of effect size and consequently the significance of detected improvement in the experimental group with respect to the control one. For instance, in the review of HernandezMolina et al. (25) the increased effect size was due to the exclusion of the study presenting the highest heterogeneity level. In our review, heterogeneity was found not only in the studies' design and the adopted outcome measures $(25,26)$, but also with respect to modality, duration, intensity if reported, and frequency of exercise programs.

For example, treatment frequency was scheduled at one to four times per week with session duration of 30 to $60 \mathrm{~min}$.

Current literature on OA collects a greater production of systematic reviews than of RCTs. Actually, we found a small amount of clinical trials.

Only 6 RCTs $(14-18,21)$ had a sample size greater than 50 subjects per group, which is the minimum amount of patients needed to consider statistically significant differ- 
WOMAC (Pain and Physical Function).

Costs: specialist medical examination, physical therapy

treatment, number of articular prosthesis surgery interventions, use of analgesic and anti-inflammatory drugs.

Physical performance: Passive tests, Six-Minute-Walk-Test,10-

Meter Walk test, Timed up and go Test, Sock Test.

Programme adherence: diary of the sessions.

Primary Outcome: WOMAC

Secondary Outcomes: Harris Hip Score (HHS), OTE (Overall

Therapy Effectiveness): patient's satisfaction and improvements with therapy.

Primary Outcome: fall risk reduction measured by PPA

(Physiological Profile Assessment).

Secondary Outcomes: Step Test e Timed up and go Test.

Physical Function and Pain both measured with WOMAC and

AIMS-SF26 (Arthritis Impact Measurement Scales 2-Short

Form). ABC Questionnaire (Activity Specific Balance Confidence

Scale): confidence in self-balance and fear of falling.
Group I: Statistically significant improvement for WOMAC

Physical Function at $6-(P=0.02)$ and 18-months follow-up $(\mathrm{P}=0.04)$.

Costs: No significant differences between Groups.

No significant differences between the two Groups

( $\mathrm{P}=0.45$ per WOMAC and $\mathrm{P}=0.79$ per $\mathrm{HHS}$ ).

Positive outcomes, maintained up to the 3-months followup, regarding both Groups.

No significant differences between the two Groups with respect to primary outcome (PPA score) and with respect to any of secondary outcomes. Results of Step Test were significant both in Group I ( $\mathrm{P}=0.004)$ and Group C (0.017). Group C: Significant improvement of time reaction $(P=0.03)$ and sensitivity to contrast $(P=0.05)$, components of PPA. ences between experimental and control groups, to guarantee homogeneity between groups and therefore to achieve golden and platinum evidence (27). With respect to treatment intensity, it is important to consider two aspects.

Firstly, prescription of series, repetitions and maximal resistance were usually not reported or, when so, resulted to be insufficient to induce modifications. Secondly, programs were often wide-focused and consisted of mixed exercises.

Different exercises in the same session, each characterized by a short duration, are not intense enough to lead to significant changes (26).

Another factor that could possibly confound the results was sample characteristics. In several studies, subjects were directly enrolled from surgery waiting lists, hence they presented an advanced stage of disorder, resulting in less responsiveness to any conservative treatment (27).

As previously mentioned, positive effects of therapeutic exercise are related to the physical function, without any significant effect on pain reduction.

The adherence to the exercise program and a frequent physical activity seem to be the most predictive factor of positive long-term outcomes $(16,28)$. Strategies that could eventually enhance exercise program adherence in the long term were phone calls, diary self-monitoring, graphic feedback and booster sessions.

Another relevant result of our review is the effectiveness of functional trainings. Education and programs addressed to the activities of daily living that are difficult to perform (activity pacing) appeared to be effective on the increasing of the global level of activity at short- and mid-term follow-up.

Moreover, the BGA approach, based on the principles of the behavioral therapy, led patients to better follow home programs and to improve physical activity in short- and long-term (17).

At long-term, this approach also seemed to reduce the risk to undergo joint prosthesis surgery (21).

The relevance of a treatment based not only on analytical exercises, but also on functional activities was confirmed by Arnold et al. (23), who demonstrated that by adding these type of programs to hydrotherapy, treatment is effective for the reduction of fall risk. On the contrary, only water programs did not show any relevant results on the same outcome (19). 
The works of Juhakoski et al. (15) and Fernandes et al. regarding exercise training, seemed to suggest its gradually increasing effect (14). In fact, despite no short-term effect was detected, WOMAC functional scale demonstrated a significant improvement at mid- and long term.

With regard to manual therapy, only two RCTs were included in this review. The moderate-quality trial of Vaarbakken and Ljunggren (20), interestingly showed differences in the treatment outcome between two strength-dosages of longitudinal traction. This could be consistent with some biomechanical studies (29), which demonstrated that, in order to provoke joint diastasis, a minimum traction force of 400 to $600 \mathrm{~N}$ is necessary (30).

This trial also seemed to confirm that manual therapy could improve pain, whereas exercise does not cause the same effect. This is consistent with the results of the work by Hoeskma et al. (2) and can suggest investigating whether a multimodal approach, combining exercise and manual therapy, could affect successfully both pain and function.

As to the positive role of exercise on use of medications, the interesting trial conducted by Juhakoski et al. (15) showed reduced use of NSAIDs at mid- and long-term follow-up. Moreover, the trial showed that exercise could improve physical function without any further cost for the health care system. Based on what has been previously mentioned, goals of future research are outlined as follows:

1. To examine population affected only by OA, not in an advanced stage;

2. To compare the effectiveness of manual therapy and therapeutic exercise programs, and to compare programs based on manual therapy only to those that combined both manual therapy and exercise, identifying the best strategies for long-term adherence;

3. To compare exercise and manual therapy programs with different modalities, intensity, duration and frequency and to compare functional tailored-programs of exercise and manual therapy with traditional ones;
4. To investigate the effectiveness of pharmacological therapy both as sole treatment, and in association with therapeutic exercise and/or manual therapy;

5. To identify predictive factors of conservative treatments, also with regard to disease progression.

\section{CONCLUSIONS}

This systematic review investigated the effectiveness of manual therapy and therapeutic exercise in the treatment of OA.

On the basis of studies we included, the evidence of effectiveness of therapeutic exercise for pain and quality of life was insufficient or limited, whereas moderate evidence was found with respect to improvement of function. Moreover, booster sessions had a positive role on increasing patient's adherence to treatment.

With regard to manual therapy, results of this review reported that joint mobilization of known dosage showed short-term reduction of pain and decreased disability compared to the same technique with unknown dosage.

Manual approaches combined with exercise addressing the whole kinetic chain of lower limb do not lead to better outcomes than the same approach only focused on the hip.

It was not possible to identify the most effective type, intensity, duration and frequency of treatment, nevertheless exercise intensity; quantity and progression of treatment did not often follow recommendations of current literature.

We suggest producing further studies of good quality with an adequate sample size, to investigate yet unexplored issues, such as type and amount of conservative treatment programs and their synergy with pharmacological treatment.

\section{REFERENCES}

1. Fransen M, McConnell S, Bell M. 1. Fransen M, McConnell S, Bell M. Therapeutic exercise for people with osteoarthritis of the hip or 
knee. A systematic review. Rheumatol. 2002; 29: $1737-45$

2. Hoeskma HL, Dekker J, Ronday HK, et al. Comparison of manual therapy and exercise therapy in osteoarthritis of the hip: a randomized clinical trial. Arthritis Rheum. 2004; 51: 722-9.

3. Cecchi F, Mannoni A, Molino-Lova R, et al. Epidemiology of hip and knee pain in a community based sample of Italian persons aged 65 and older. Osteoarthritis Cartilage. 2008; 16: 1039-46.

4. Mannoni A, Briganti MP, Di Bari M, et al. The epidemiological profile of symptomatic osteoarthritis in older adults: a population-based study in Dicomano, Italy. Ann Rheum Dis. 2003; 62: 576-8.

5. Salaffi F, De Angelis R, Grassi W. Prevalence of musculoskeletal conditions in an Italian population sample: results of a regional community-based study. Clin Exper Rheumatol. 2005; 23: 819-28.

6. Cibulka MT, White DM, Woehrle J, et al. Hip pain and mobility deficits-hip osteoarthritis: clinical practice guidelines linked to international clessification of functioning, disability, and health from orthopaedic section of the American Physical Therapy Association. J Orthop Sports Phys Ther. 2009; 39: A1-25.

7. Birrell F, Croft P, Cooper C, et al. Predicting radiographic hip osteoarthritis from range of movement. Rheumatology (Oxford). 2001; 40: 506-12.

8. Altman R, Alarcón G, Appelrouth D, et al. The American College of Rheumatology criteria for the classification and reporting of osteoarthritis of the hip. Arthritis Rheum. 1991; 34: 505-14.

9. Zhang W, Doherty M, Arden N, et al. EULAR evidence based recommendations for the management of hip osteoarthritis: report of a task force of the EULAR Standing Committee for International Clinical Studies Including Therapeutics (ESCISIT). Ann Rheum Dis. 2005; 64: 669-81.

10. Hochberg MC, Altman RD, April KT, et al. American College of Rheumatology 2012 recommendations for the use of nonpharmacologic and pharmacologic therapies in osteoarthritis of the hand, hip, and knee. Arthritis Care Res (Hoboken). 2012; 64: 465-74.

11. Hoeksma HL, Dekker J, Ronday HK, et al. Manual therapy in osteoarthritis of the hip: outcome in subgroups of patients. Rheumatology (Oxford) 2005; 44: 461-12.

12. Shrier I, Feldman DE, Gaudet MC, et al. Conservative non-pharmacological treatment options are not frequently used in the management of hip osteoarthritis. J Sci Med Sport. 2006; 9: 81-6.

13. Moseley AM, Herbert RD, Sherrington C, Maher CG. Evidence for physiotherapy prac- tice: a survey of the Physiotherapy Evidence Database (PEDro). Aust J Physiother. 2002; 48: 43-9.

14. Fernandes L, Storheim K, Sandvik L, et al. Efficacy of patient education and supervised exercise vs patient education alone in patient with hip osteoarthritis: a single blind randomized clinical trial. Osteoarthritis Cartilage. 2010; 18: 1237-43.

15. Juhakoski R, Tenhonen S, Malmivaara A, et al. A pragmatic randomized controlled study of the effectiveness and cost consequences of exercise therapy in hip osteoarthritis. Clin Rehabil 2011; 25: 370-83.

16. Pisters MF, Veenhof C, Schellevis FG, et al. Long-term effectiveness of exercise therapy in patients with osteoarthritis of the hip or knee: a randomized controlled trial comparing two different physical therapy interventions. Osteoarthr. Cartil. 2010; 18: 1019.

17. Pisters MF, Veenhof C, de Bakker DH, et al. Behavioural graded activity results in better exercise adherence and more physical activity than usual care in people with osteoarthritis: a cluster-randomised trial. J Physiother. 2010; 56: 41-7.

18. Murphy SL, Strasburg DM, Lyden AK, et al. Effects of activity strategy training on pain and physical activity inolder adults with knee or hip osteoarthritis: a pilot study. Arthritis Rheum. 2008; 59: 1480-7.

19. Hale LA, Waters D, Herbison P. A randomized controlled trial to investigate the effects of water based exercise to improve falls risk and physical function in older adults with lowerextremity osteoarthritis. Arch Phys Med Rehabil. 2012; 93: 27-34.

20. Vaarbakken K, Ljunggren AE. Superior effect of forceful compared with standard traction mobilizations in hip disability? Adv Physiother. 2007; 9: 117-28.

21. Branthingham JW, Parkin-Smith G, Cassa TK, et al. Full kinetic chain manual and manipulative therapy plus exercise compared with targeted manual and manipulative therapy plus exercise for symptomatic osteoarthritis of the hip: a randomized controlled trial. Arch Phys Med Rehabil. 2012; 93: 25967.

22. Shrier I, Zukor D, Boivin J, et al. The feasibility of a randomized trial using a progressive exercise program in patients with severe hip osteoarthritis. J Muscoskel Pain. 2008; 16: 309-17.

23. Arnold CM, Faulkner RA. The effect of aquatic exercise and education on lowering fall risk in older adults with hip osteoarthritis. J Aging Phys Activity. 2010; 18: 245-60.

24. Bennell KL, Hinman RS. A review of the clinical evidence for exercise in osteoarthritis of the hip. J Sci Med Sport. 2011; 14: 4-9.

25. Hernández-Molina G, Reichenbach S, Zhang 
B, et al. Effect of therapeutic exercise for hip osteoarthritis pain: results of a meta-analysis. Arthritis Rheum. 2008; 59: 1221-8.

26. McNair PJ, Simmonds MA, Boocock MG, Larmer PJ. Exercise therapy for the management of osteoarthritis of the hip joint: a systematic review. Arthritis Res Ther. 2009; 11: R98.

27. Fransen M, McConnell S, Hernandez-Molina G, Reichenbach S. Exercise for Osteoarthritis of the hip. Cochrane Database Syst Rev. 2009; 8: CD007912.

28. Pisters MF, Veenhof C, van Meeteren NL, et al. Long-term effectiveness of exercise therapy in patients with osteoarthritis of the hip or knee: a systematic review. Arthritis Rheum. 2007; 57: 1245-53.

29. Brantingham JW, Globe G, Pollard H, et al. Manipulative therapy for lower extremity conditions: expansion of literature review. J Manipulative Physiol Ther. 2009; 32: 53-71.

30. Arvidsson I. The hip joint: forces needed for distraction and appearance of the vacuum phenomenon. Scand J Rehabil Med. 1990; 22: 157-61. 